\title{
A PRIMAZIA DO JUSTO SOBRE O BEM NA FILOSOFIA POLÍTICA DE JOHN RAWLS
}

The primacy of Just over the Good in political philosophy John Rawls

\author{
Lucas Mateus Dalsotto*
}

Resumo: O presente estudo tem como finalidade discutir a primazia do justo sobre o bem na filosofia política de John Rawls, apresentada especialmente em seus textos mais importantes, tais como Uma teoria da justiça, Liberalismo político e Justiça e Democracia. A ideia da primazia do justo sobre o bem, em diversas situações, é interpretada de modo equivocada, uma vez que se toma essa afirmação de Rawls como se justiça como equidade não carecesse não qualquer noção de bem, o que o autor nega constantemente. Assim sendo, o presente artigo tem por pretensão inicialmente apresentar em que sentido a teoria de rawlsiana é política e não metafísica ou epistemológica. Tentaremos desfazer alguns mal-entendidos que envolvem essa discussão e mostrar os argumentos de Rawls para a fundamentação de uma teoria política de justiça. Em seguida, iremos expor a ideia de consenso sobreposto e sua função na estruturação de justiça como equidade no que tange a ideia da primazia do justo sobre o bem.

Palavras-chave: Rawls. Justo. Primazia. Bem.

\begin{abstract}
This paper aims to discuss the primacy of the right over the good in the political philosophy of John Rawls, shown especially in his most important texts such as $A$ theory of justice, Political liberalism and Justice and Democracy. The idea of the primacy of the right over the good, in many situations, is interpreted in a wrong way, since it takes that statement as Rawls justice as fairness is not necessitated no notion of good, which the author denies constantly. Therefore, this article is to claim initially present in what sense the Rawlsian theory is political and not metaphysical or epistemological. We will try to dispel some misunderstandings surrounding this debate and show the arguments of Rawls for reasons of a political theory of justice. Then we expose the idea of overlapping consensus and its function in structuring justice as fairness regarding the idea of the primacy of the fair on the well.
\end{abstract}

Keywords: Rawls. Right. Primacy. Good.

\footnotetext{
* Doutorando do PPG em Filosofia da Universidade Federal de Santa Maria (UFSM). Bolsista CAPES. Contato: lmdalsotto@hotmail.com
}

\begin{tabular}{|c|c|c|c|c|c|}
\hline intuitio & $\begin{array}{c}\text { ISSN } \\
1983-4012\end{array}$ & Porto Alegre & Vol.7 $-\mathrm{N}^{\circ} .1$ & $\begin{array}{c}\text { Junho } \\
2014\end{array}$ & p.125-138 \\
\hline
\end{tabular}




\section{Colocando o problema}

A ideia da primazia do justo sobre o bem é um elemento essencial da filosofia política rawlsiana, de modo que não se pode compreender corretamente a teoria da justiça como equidade sem conceber os termos de tal primazia. Entretanto, a ideia da prioridade do justo pode gerar malentendidos $^{1}$, por isso a mesma não deve ser compreendida como a independência ou a dissociação entre os conceitos de justo e de bem, mas sim como uma relação apropriada entre ambos. Essa prioridade não implica necessariamente em uma concepção de bem que seja instrumental, tal como para o utilitarismo ${ }^{2}$, pois o justo e o bem são complementares e nenhuma concepção de justiça pode se basear inteiramente no correto (right) ou no bem ( good).

Rawls quer com justiça como equidade apresentar a estrutura de uma teoria razoavelmente alternativa ao utilitarismo. Ao afirmar a primazia do justo sobre o bem, ele tenta escapar a duas fortes objeções, a saber: (i) a de que sua teoria seria intolerante em relação a certas concepções de bem (como doutrinas religiosas antiindividualistas) (ii) ou então que, pela neutralidade a que sua teoria se propunha, a mesma conduziria ao ceticismo diante das demais concepções de bem presentes numa sociedade pluralista.

Deste modo, pelo menos duas questões prévias se colocam à discussão, as quais podem ser feitas nos seguintes termos: (i) como é possível que justiça como equidade se valha de ideias do bem sem fazer afirmações sobre a verdade desta ou daquela doutrina abrangente ${ }^{3}$ (concepção do que seja o bem) e (ii) em que sentido o justo tem prioridade sobre o bem na teoria de Rawls? Em resposta a está última questão, para Vita, a justiça tem primazia sobre o bem em dois sentidos fundamentalmente: "primeiro porque [os princípios de justiça] podem ser defendidos de forma que não pressupõem a validade de nenhuma visão específica de bem e segundo porque colocam limites às formas pelas quais os cidadãos podem se empenhar em realizar as concepções do bem que julgam ser verdadeiras"”.

Grosso modo, a tese rawlsiana assentada sobre tal primazia é a de que os princípios de justiça impõem limites aos modos de vidas que são amplamente aceitáveis em uma sociedade democrática. Esses cerceamentos são eles próprios, em certo sentido, um bem, são o "bem da justiça". Logo, as reivindicações feitas pelos cidadãos às instituições que transgridam os limites fixados pelos princípios de justiça, são desconsideradas. No entanto, a teoria de Rawls é suficientemente aberta para comportar um amplo espectro de modos de vida e concepções de bem capazes de motivar os contratantes a

\footnotetext{
${ }^{1}$ RAWLS, John. Justiça e democracia; tradução Irene A. Paternot; seleção, apresentação e glossário Catherine Audard. São Paulo: Martins Fontes, 2000.p. 293.

${ }^{2}$ Braga reforça essa ideia quando afirma que teoria deontológica- contratualistas, tal como a de Rawls, defende a ideia de que o justo tem primazia sobre o bem na medida em que o deontologismo-contratualista não aceita que o correto seja reduzido ao globalmente bom ou a uma determinada concepção de bem (BRAGA, Antonio F. S. Kant, Rawls e o utilitarismo: justiça e bem na filosofia política contemporânea. Rio de Janeiro: Contraponto, 2011, p. 33).

${ }^{3}$ RAWLS, John. O Liberalismo político. 1 ed. amp. São Paulo: M. Fontes, 2011. p. 204.

${ }^{4}$ VITA, Álvaro de. A justiça igualitária e seus críticos. $2^{\circ}$ ed. São Paulo: WFM Martins Fontes, 2007. p. 18.
}

\begin{tabular}{|c|c|c|c|c|c|}
\hline intuitio & $\begin{array}{c}\text { ISSN } \\
1983-4012\end{array}$ & Porto Alegre & Vol.7 - N .1 & $\begin{array}{c}\text { Junho } \\
2014\end{array}$ & p.125-138 \\
\hline
\end{tabular}


devotarem-se a elas. "Em suma, a justiça estabelece os limites, o bem indica a finalidade. Assim, o justo e o bem são complementares, o que a prioridade do justo não nega em absoluto" ${ }^{5 "}$.

Quanto à primeira questão que há pouco formulamos, o que evita que se façam afirmações a respeito da verdade de determinadas ideias do bem, é o fato de que Rawls está discutindo os pressupostos de uma concepção política de justiça e não de uma doutrina moral, religiosa ou filosófica abrangente ${ }^{6}$. Isso quer dizer fundamentalmente que tal concepção política de justiça precisa respeitar formas variadas dos indivíduos compreenderem o bem, intervindo somente em casos em que alguma concepção particular de bem estiver em desacordo com os princípios contrafactualmente acordados.

Por isso,

[a]s características de uma concepção política são, em primeiro lugar, que é aquela concepção moral concebida para um campo específico, a estrutura básica de um regime democrático constitucional; em segundo lugar, que o fato de se aceitar essa concepção política não pressupõe a aceitação de uma doutrina abrangente particular qualquer. Ao contrário, a concepção política pretende valer unicamente para a estrutura básica. E, em terceiro lugar, que ela é formulada não nos termos de uma doutrina abrangente qualquer, mas nos de certas ideias intuitivas fundamentais, consideradas como latentes de uma cultura política pública de uma sociedade democrática ${ }^{7}$.

\section{Justiça como equidade: uma teoria política}

Em vários escritos, Rawls chama atenção para o fato de que sua teoria não tem por pretensão se utilizar de teorias do bem específicas (religiosas, morais ou filosóficas) ou então de fazer afirmações a respeito de uma teoria que se pretenda ser verdade universal. Pelo contrário, o autor quer mostrar que sua teoria dispensa esse tipo de argumentação, pois, numa democracia constitucional, "a concepção pública de justiça deve ser, tanto quanto possível, independente de doutrinas religiosas e filosóficas sujeitas a controversas ${ }^{8}$ ". É exatamente para deixar claro esse ponto que Rawls escreve um artigo intitulado A teoria da justiça como equidade: uma teoria política, e não metafísica.

Rawls tem ciência de não ter deixado amplamente claro em Uma teoria da justiça e em outros escritos que a teoria da justiça como equidade deveria ser interpretada como uma concepção política de justiça. Seria um equívoco, em certo sentido, dizer que a concepção política de justiça rawlsiana é também uma concepção moral ${ }^{9}$, uma vez que a teoria de Rawls faz afirmações a propósito de como os conceitos de correto (right) e de bem (good) devem ser relacionados no interior de uma teoria moral e

\footnotetext{
${ }^{5}$ RAWLS, John. Uma teoria da justiça. 3.ed. rev. São Paulo: M. Fontes, 2008. p. 294.

${ }^{6}$ Com o termo abrangente Rawls $(2000$, p. 295) compreende "as concepções daquilo que tem valor para a existência humana, os ideais referentes à virtude e ao caráter pessoais, ideais que influenciam boa parte da nossa conduta não política (e praticamente toda a nossa existência)".

${ }^{7}$ RAWLS, 2000, p. 295.

${ }^{8}$ RAWLS, 2000, p. 202.

${ }^{9}$ A teoria política de Rawls faz uso de uma teoria moral na estruturação dos conceitos de correto (right) e de bem (good), mas não é uma concepção moral em sentido estrito.
}

\begin{tabular}{|c|c|l|l|l|l|}
\hline intuitio & $\begin{array}{c}\text { ISSN } \\
1983-4012\end{array}$ & Porto Alegre & Vol.7- $\mathrm{N}^{\circ} .1$ & $\begin{array}{c}\text { Junho } \\
2014\end{array}$ & p.125-138 \\
\hline
\end{tabular}


não sobre qual ideia de bem é a melhor ou qual produz maior utilidade agregada, no caso do utilitarismo $^{10}$. A interpretação correta dessa ideia de Rawls conviria em argumentar que a teoria da justiça como equidade é feita para ser aplicada a um determinado tipo de objeto, isto é: as instituições econômicas, sociais e políticas, ou, se quisermos, a estrutura básica de uma sociedade democrática ${ }^{11}$.

De igual modo, seria também incorreto afirmar que a teoria de Rawls representa a aplicação de uma concepção moral geral (abrangente) à estrutura básica da sociedade, de modo que essa estrutura fosse um dos casos onde tal concepção moral se aplicasse. Claramente, Kant e Mill, a despeito de suas importantes contribuições ao pensamento liberal, apresentaram ideais morais como o fundamento válido de um regime democrático. Apresentaram respectivamente os ideais da autonomia $^{12} \mathrm{e}$ da individualidade $^{13}$ como princípios de uma concepção moral abrangente que deveria se aplicar à sociedade $^{14}$. Mas esse, não é o caso de Rawls.

É exatamente do ponto de vista político de justiça como equidade que a teoria rawlsiana se dissocia totalmente, por exemplo, da teoria moral utilitarista, visto que essa última aplica o princípio da utilidade, qualquer que seja a sua formulação, a todos os tipos de objeto e cursos de ações. O princípio da utilidade, a não ser segundo a interpretação do utilitarismo de regras ${ }^{15}$, aplica-se indistintamente a todas as formas sociais, tanto públicas e institucionais quanto privadas e pessoais. Uma teoria geral como o utilitarismo rejeita a ideia de que hajam princípios fundamentais de justiça que sejam politicamente reconhecidos e que não compartilhem de nenhuma concepção moral específica ${ }^{16}$. Grosso modo, a questão que precisa razoavelmente estar clara é que nenhuma concepção moral geral pode fornecer um fundamento publicamente reconhecido e aceito pelos cidadãos para uma concepção de justiça em um Estado democrático.

Para fins de elucidação do argumento, basta olharmos para nossa experiência histórica. Não são poucos os períodos durante os quais determinadas questões fundamentais foram alvos de

${ }^{10}$ Aqui parece haver um ponto que carece de maiores explicações e estudos acerca da teoria de Rawls. Embora ele seja categórico em afirmar que sua teoria deve ser entendida como uma teoria política, o mesmo claramente utiliza-se de um modelo de justificação moral (não no sentido de doutrinas abrangestes, mas no sentido de uma justificação moral) no momento em que divide a sua teoria em dois estágios: (i) o da justificação moral independente e autossustentada (ii) e o da estabilidade social e política a partir de um consenso sobreposto. Se essa interpretação está correta, então é possível afirmar que existe uma relação muito próxima entre moral e política, sendo inclusive uma relação de complementariedade entre ambas.

${ }^{11}$ FORST, Rainer. Contextos de Justiça: filosofia política para além de liberalismo e comunitarismo. São Paulo: Boitempo, 2010, p. 223.

${ }^{12}$ Ver KANT, Immanuel. Fundamentação da metafísica dos costumes. Trad. de Guido Antônio de Almeida. São Paulo: Discurso Editorial: Barcarolla, 2009, Seção III.

${ }^{13}$ Ver MILL, John Stuart. A liberdade. São Paulo: Martins Fontes, 2000.

${ }^{14}$ RAWLS, 2000, p.. 233.

${ }^{15} \mathrm{O}$ termo utilitarismo das regras pode designar coisas variavelmente diferentes dado ao modo como se pode empregá-lo. David Lyons assim diz "in order to discuss the various types of rule-utilitarianism, it is necessary to distinguish different ways in which rules can be grounded in utility. I shall distinguish, for example, between theoretical (or theory-dependent) rules and merely cautionary rules (rules of thumb). We may say, for the present, that theoretical rules are rigorously justified by a given principle; they are normally incorporated essentially into a rule-utilitarianism properly so-called; they are rules on the basis of which the rightness or wrongness of particular acts in determined and they often cannot be dispensed with in the application of such a theory" (LYONS, David. Forms and limits of utilitarianism. Oxford: Oxford University Press, 2002. p. 119).

${ }^{16}$ RAWLS, 2000, p. 7.

\begin{tabular}{|c|c|l|l|l|l|}
\hline intuitio & $\begin{array}{c}\text { ISSN } \\
1983-4012\end{array}$ & Porto Alegre & Vol.7- $\mathrm{N}^{\mathrm{o}} .1$ & $\begin{array}{c}\text { Junho } \\
2014\end{array}$ & p.125-138 \\
\hline
\end{tabular}


profundas controversas e que acabaram acarretando na inexistência completa de qualquer base comum de acordo político. No decorrer do pensamento democrático, existiu permanentemente uma discordância a respeito de qual seria a melhor forma (mais razoável) de organizar e efetivar os valores da liberdade e da igualdade na estrutura básica da sociedade. A teoria da justiça como equidade pretende ser uma teoria que busca discutir criticamente estas questões. Entretanto, talvez fosse prudente questionarmos que, em havendo uma teoria que pretenda discutir essa complexa problemática, de que forma ela faria isso.

É evidente que o melhor que a teoria de Rawls consegue fazer é minimizar e limitar a extensão dessa discordância pública sobre as controversas políticas mais importantes, dado a impossibilidade de se alcançar uma concordância completa e estável acerca das mesmas. Destarte, na construção de uma concepção política de justiça, Rawls parte de convicções fortes e solidamente comungadas pelos cidadãos em uma sociedade democrática. Por exemplo, contemporaneamente a escravidão é considerada como intrinsecamente injusta e, muito embora possam ainda existir vestígios da escravidão em práticas sociais ou atitudes inconfessas, é possível dizer que ninguém razoavelmente a defenderia. Partir de convicções amplamente sólidas e evidentes como a do repúdio à escravidão, coloca as balizas que qualquer concepção de justiça precisa levar em conta para ser razoável e estável numa sociedade democrática marcada pela existência de concepções de bem em conflito e incomensuráveis entre si.

Quando Rawls sustenta que uma concepção de justiça precisa estar de acordo com nossos juízos morais ponderados ${ }^{17}$, ele nada mais faz do que inserir uma importante cláusula no argumento, a saber: que essa concepção política de justiça nos proporciona um ponto de vista publicamente reconhecido sobre o qual podemos avaliar "se as instituições sociais e políticas são ou não justas ${ }^{18 "}$. A validade desses princípios não está ligada a pressupostos empiricamente comprovados pelas ciências em geral ou então por ideais metafísicos de doutrinas abrangentes. Pelo contrário, os pressupostos de uma teoria da justiça devem estar de acordo com os juízos morais ponderados que são publicamente reconhecidos ${ }^{19}$.

Obviamente alguém poderia contestar essa tese afirmando que em algumas situações os juízos morais podem se mostrar contraditórios entre si, de modo que seria difícil atribuir primazia a certa concepção específica de justiça. Nesse caso, seria preciso que nossos juízos morais fossem organizados de forma coerente, sistemática e ponderada. No entanto, na teoria rawlsiana a tarefa de organizar de modo coerente ${ }^{20}$ e sistemático nossos juízos morais é da posição original. Ela garante que

17 Quando Rawls argumenta que nossos juízos morais ponderados são necessários para avaliarmos a razoabilidade de qualquer teoria da justiça, ele não precisa pressupor a existência de nenhuma verdade moral objetiva. Não é preciso, por exemplo, afirmar que existe um "ideal" de justiça que condena a escravidão.

${ }^{18}$ RAWLS, 2000, p. 210.

${ }^{19}$ RAWLS, 2008, p. 153-6.

${ }^{20}$ Essa é uma discussão importante a respeito de se a posição original deve ser entendida como um procedimento coerentista ou um procedimento fundacionalista. Segundo Silveira, a posição original é uma tentativa de harmonizar em um único sistema os pressupostos filosóficos razoáveis para a determinação de

\begin{tabular}{|c|c|l|l|l|l|}
\hline intuitio & $\begin{array}{c}\text { ISSN } \\
1983-4012\end{array}$ & Porto Alegre & Vol.7 $-\mathrm{N}^{\mathrm{o}} .1$ & $\begin{array}{c}\text { Junho } \\
2014\end{array}$ & p.125-138 \\
\hline
\end{tabular}


o resultado seja um conjunto sistemático de princípios de justiça ${ }^{21}$, de tal forma que seja possível estabelecer a prioridade entre valores conflitantes a partir de premissas amplamente aceitas e genéricas $^{22}$.

Argumentar a partir de premissas gerais, embora ainda fracas, ajuda para que se chegue a conclusões mais específicas. Portanto, a posição original serve para "unificar nossas convicções mais ponderadas, em todos os níveis de generalidade, e aproximá-las umas das outras a fim de alcançar um acordo mútuo ${ }^{23 "}$ " a respeito de como devemos compreender as questões de justiça no interior de uma sociedade democrática.

A ideia aqui é simplesmente tornar nítidas para nós mesmos as restrições que parecem razoáveis impor a argumentos a favor de princípios de justiça e, por conseguinte, a esses próprios princípios. Assim, parece razoável e de modo geral aceitável que ninguém deva ser favorecido pelo acaso ou pelas circunstâncias sociais na escolha dos princípios. Também parece haver consenso geral de que deve ser impossível adaptar os princípios às circunstâncias de casos especiais ${ }^{24}$.

Logo, o objetivo da teoria da justiça como equidade não é nem metafísico e nem epistemológico, mas prático ${ }^{25}$. Ela não se apresenta como uma concepção verdadeira sob a qual todas as ações privadas e públicas devam ser reguladas, mas sim como a mais razoável no que tange a justiça da estrutura básica da sociedade. Se a teoria de Rawls não elimina todos os conflitos existentes entre as concepções de bem existentes, então ela ao menos permite que se consiga visualizar de que maneira a unidade de uma sociedade poderia ser possível e estável ${ }^{26}$.

Para que seja possível aprofundar esse ponto, é preciso que falemos, mesmo que sucintamente, sobre duas ideias: (ii) a sociedade entendida como um sistema equitativo de cooperação (ii) e a concepção política de pessoa. Passemos, então, a primeira ideia.

2.1 A sociedade como um sistema equitativo de cooperação

princípios e juízos morais sobre a justiça (SILVEIRA, D.C. Posição Original e Equilíbrio reflexivo em John Rawls: o Problema da Justificação. In: Trans/Form/Ação, vol.32, no.1, 2009). Rawls (2008, p. 20) mesmo deixa isso claro quando diz: "[e]u não defendo que os princípios de justiça propostos sejam verdades necessárias ou deriváveis dessas verdades. Uma concepção de justiça não pode ser deduzida de premissas autoevidentes ou de condições impostas aos princípios; ao contrário, sua justificação é uma questão de apoio mútuo de várias considerações, do ajuste de todas as partes em uma visão coerente".

${ }^{21}$ SILVEIRA, Denis.C. Epistemologia Coerentista em Rawls. In: Dissertatio [34], 2011. p.163-4.

${ }^{22}$ RAWLS, 2008, p. 28.

${ }^{23}$ RAWLS, 2000, p. 223.

${ }^{24}$ RAWLS, 2008, p. 22.

${ }^{25}$ RAWLS, 2000, p. 211.

${ }^{26}$ Christine Korsgaard argumenta exatamente nessa direção quando afirma que "a filosofia prática, como concebida por Kant e Rawls, não é uma questão de encontrar o conhecimento para aplicar na prática. Antes, ela é o uso da razão para resolver problemas práticos" (KORSGAARD, Christine M. Realism and Constructivism in Twentieth-Century Moral Philosophy. In: Philosophy in America at the Turn of the Century. Journal of Philosophical Research, 2003, p. 99-122).

\begin{tabular}{|c|c|l|l|l|l|}
\hline intuitio & $\begin{array}{c}\text { ISSN } \\
1983-4012\end{array}$ & Porto Alegre & Vol.7- $\mathrm{N}^{\mathrm{o}} .1$ & $\begin{array}{c}\text { Junho } \\
2014\end{array}$ & p.125-138 \\
\hline
\end{tabular}


A ideia intuitiva central que permite ligar as demais ideias básicas sistematicamente entre si é que a sociedade se estabelece como um sistema equitativo de cooperação entre pessoas livres e iguais durante todas as suas vidas. Segundo Rawls, existe uma cultura pública de cooperação social que cria uma identidade de interesses entres os membros, ao mesmo tempo que, existe também uma variedade de conflitos próprios de uma cultura democrática. Nesse caso, o papel da justiça é ser o ponto de vista comum sobre o qual se avalia as reivindicações conflitantes feitas às instituições econômicas, sociais e políticas.

No entanto, para sermos precisos na apresentação da ideia de cooperação social, vamos nos valer de três ideias que Rawls apresenta para ilustrá-la, a saber: (i) a cooperação social é regida por regras que são publicamente reconhecidas e por procedimentos que são seguidos por aqueles que cooperam, (ii) a cooperação social implica que os princípios contrafactualmente acordados sejam equitativos e aceitos por todos, assim como os termos da cooperação sugerem uma ideia de reciprocidade e intergeracionalidade (iii) e por fim, a cooperação social exige que se tenha a ideia de vantagem racional de cada participante em atingir a consecução de seu bem específico ${ }^{27}$.

A sociedade como um sistema equitativo de cooperação social deve também ser entendida como um sistema mais ou menos completo e autossuficiente, capaz de ser estável no decorrer do tempo. Rawls assevera ainda que ela não deve ser entendida como uma associação com objetivos limitados ou muito específicos, pois os indivíduos não entram nela voluntariamente, mas nascem nela. Nesse caso, a ideia de cooperação social só faz sentido à luz de uma concepção de pessoa que esteja de acordo com ela.

\subsection{A concepção política de pessoa}

É evidente que existem diversos elementos da natureza humana que poderiam ser tomados para discutir o problema da justiça. Mas para Rawls, a natureza humana em justiça como equidade é entendida como uma concepção política de pessoa (cidadão ${ }^{28}$ ). Seria um equívoco confundir a concepção política de pessoa com uma análise da natureza humana sob o ponto de vista das ciências humanas ou então da teoria social. No artigo The Independence of moral theory, Rawls retoma esse ponto argumentando que a concepção política de pessoa foi pensada em sentido normativo para o modelo de representação da posição original, diferentemente de uma teoria da natureza humana onde as estruturas são preenchidas em função de fatos gerais próprios dos seres humanos ${ }^{29}$.

Essa concepção política de pessoa está baseada em ideias básicas intuitivas presentes na cultura pública de uma democracia. Sendo as pessoas membros integrais de um sistema equitativo de

\footnotetext{
${ }^{27}$ RAWLS, 2000, p. 215.

28 Dados os objetivos da teoria da justiça como equidade, essa concepção política de pessoa concebe os indivíduos como cidadãos.

${ }^{29}$ RAWLS, John. The Independence of moral theory. FREEMAN, Samuel. Collected Papers. Cambridge: Cambridge University Press, 1999. p. 321.
}

\begin{tabular}{|c|c|l|l|l|l|}
\hline intuitio & $\begin{array}{c}\text { ISSN } \\
1983-4012\end{array}$ & Porto Alegre & Vol.7 $-\mathrm{N}^{\mathrm{o}} .1$ & $\begin{array}{l}\text { Junho } \\
2014\end{array}$ & p.125-138 \\
\hline
\end{tabular}


cooperação social, elas possuem dois interesses superiores da personalidade moral, um senso de justiça e uma concepção de bem, e são entendidas como livres e iguais. Mas essa descrição dos indivíduos não pode nos fazer pensar que a concepção política de pessoa pressuponha uma doutrina metafísica a respeito da mesma. Embora a ideia de pessoas livres possa sugerir isso, os cidadãos consideram-se livres politicamente em três sentidos. Examinemos brevemente cada um deles.

Em primeiro lugar, os cidadãos são livres pelo fato de conceberem a si mesmos e aos demais como moralmente capazes de possuir a faculdade moral de ter uma concepção de bem. Mas isso não pode ser entendido de forma que se considerem inevitavelmente ligados à efetivação de uma estrita concepção de bem. Pelo contrário, são livres enquanto capazes de rever e mudar suas concepções de bem em função de motivos particulares que sejam razoáveis. A liberdade de cada cidadão é independente de qualquer concepção de bem particular ou específica, pois a ideia de cidadãos como pessoas livres é política. Mesmo que os cidadãos revejam e alterem suas concepções de bem, suas identidades ${ }^{30}$ são públicas. Isso quer dizer que, se em um dado momento algum cidadão converter-se de uma religião para outra ou então sair de alguma instituição e entrar em outra, "não deixa de ser, no que diz respeito às questões de justiça política, a mesma pessoa de antes ${ }^{31}$ ”. Historicamente, não faltam situações em que os direitos básicos estiveram ligados, por exemplo, a filiação religiosa ou a classe social.

Em segundo lugar, os cidadãos consideram-se livres na medida em que são fontes autoautenticadas de reivindicações legítimas. Eles fazem reivindicações às instituições competentes com a intenção de que elas sejam ouvidas e efetivadas, independentemente do fato das exigências estarem ou não intimamente de acordo com os deveres e obrigações especificados pela concepção política de justiça. As reivindicações podem ser oriundas de concepções específicas de bem e ao mesmo tempo serem legítimas e autênticas. O único requisito necessário é que essas reivindicações respeitem os limites dados pela concepção política de justiça previamente acordados. Rawls usa o exemplo da escravidão ${ }^{32}$ para ilustrar esse ponto. Os escravos não são considerados como fontes autoautenticadas de reivindicações legítimas, nem mesmo como possuidores de direitos e deveres. Simplesmente não "são reconhecidos publicamente como pessoas ${ }^{33}$ ".

Em terceiro e último lugar, os cidadãos entendem-se como livres porque são capazes de assumir responsabilidade sobre seus próprios fins, limitando assim, suas reivindicações no que diz respeito à justiça permitida pelos princípios contratualmente acordados. Os cidadãos são capazes de ajustar suas demandas de acordo com aquilo que podem razoavelmente esperar obter. Por isso, o valor de suas exigências não se mede pela força de suas necessidades, mesmo que estas sejam justas e

\footnotetext{
${ }^{30}$ É prudente deixar claro que não estamos interessados em discutir o problema da identidade pessoal. Quando falamos em identidade pública estamos nos referindo especificamente ao fato de que não há a mutabilidade de direitos de nenhum cidadão pelo mesmo rever e modificar sua concepção específica de bem.

${ }^{31}$ RAWLS, 2011, p. 37.

${ }^{32}$ RAWLS, 2011, p. 38.

${ }^{33}$ RAWLS, 2000, p. 230.
}

\begin{tabular}{|c|c|l|l|l|l|}
\hline intuitio & $\begin{array}{c}\text { ISSN } \\
1983-4012\end{array}$ & Porto Alegre & Vol.7 $-\mathrm{N}^{\circ} .1$ & $\begin{array}{l}\text { Junho } \\
2014\end{array}$ & p.125-138 \\
\hline
\end{tabular}


legítimas. A questão aqui é que, se partimos da ideia intuitiva básica de que a sociedade é um sistema de cooperação social, então somos membros envolvidos na cooperação social e que, portanto, precisamos ajustar nossos fins segundo essa ideia. Está implícito nisso o pressuposto de que somos responsáveis uns pelos outros. Mas é importante também dizer que isso não nega em absoluto o fato de que os cidadãos são livres para construírem a si próprios e fazerem suas próprias escolhas, uma vez que essa é uma das partes da personalidade moral das pessoas (ter uma concepção de bem).

\section{A ideia de consenso sobreposto}

Visto que justiça como equidade é uma concepção política que pressupõe a ideia da sociedade como um sistema equitativo de cooperação social e uma concepção política de pessoa, precisamos agora explicitar de forma mais sistemática a ideia de consenso sobreposto. Segundo Rawls ${ }^{34}$, os fins de uma concepção política de justiça se fixam a partir da ideia de sociedade que se tem. Por exemplo, em uma sociedade democrática constitucional, a qual nos interessa nessa discussão, a concepção política de justiça não pode somente se limitar a dar as bases da justificação das instituições políticas e sociais sobre a qual os contratantes devem estar de acordo, mas também deve garantir a estabilidade dessa concepção no decorrer de uma geração a outra.

Para isso, a ideia de consenso sobreposto reafirma fortemente alguns pressupostos já discutidos sobre a concepção política de justiça. Eles podem ser resumidamente apresentados da seguinte maneira: (i) uma concepção política de justiça deve ser elaborada para um determinado fim, a estrutura básica da sociedade, (ii) ela não pode ser derivada de concepções abrangentes de bem (iii) e tal concepção deve estar fundada em certas intuições fundamentais latentes próprias de uma cultura democrática $^{35}$, de forma que esta seja familiar para a maioria dos cidadãos. A partir dessas ideias, podemos pressupor obter apoio de cidadãos livre e iguais por meio de um consenso sobreposto a propósito de uma concepção política de justiça.

Quando se diz que os cidadãos devem ser entendidos como pessoas livres e iguais, afirmamos que tais ideais devem ser entendidos na linguagem de uma cultura democrática pública e aplicados às exigências das instituições fundamentais. A ideia é que a concepção de justiça a qual esses ideais pertencem ganhe respaldo também de outras doutrinas abrangentes por meio de um consenso sobreposto. Caso contrário, um acordo público a respeito da justiça baseado em uma única concepção abrangente de bem somente poderia ser mantida por meio de um poder tirânico ${ }^{36}$.

Todavia, alguém poderia contestar a ideia de consenso sobreposto sustentando que a mesma deveria ser rejeitada, visto que ela "abandona a esperança de encontrar uma comunidade política e se

\footnotetext{
${ }^{34}$ RAWLS, 2000, p. 245.

35 Rawls (2011, p. 16) descreve essa cultura democrática pública como "uma tradição de pensamento democrático, cujo conteúdo é pelo menos familiar e inteligível ao senso comum educado dos cidadãos em geral".

${ }^{36}$ RAWLS, 2000, p. 252.
}

\begin{tabular}{|c|c|c|c|c|c|}
\hline intuitio & $\begin{array}{c}\text { ISSN } \\
1983-4012\end{array}$ & Porto Alegre & Vol.7 $-\mathrm{N}^{\circ} .1$ & $\begin{array}{c}\text { Junho } \\
2014\end{array}$ & p.125-138 \\
\hline
\end{tabular}


satisfaz, em vez disso, com um entendimento público que no fundo não passa de um modus vivendi ${ }^{37}$ ". O contra-argumento rawlsiano consiste em ressaltar que essa esperança da comunidade política deve ser deixada de lado, se por isso, a entendemos como ligada a uma mesma doutrina abrangente. $\mathrm{O}$ liberalismo recusa o entendimento da sociedade política como uma comunidade ligada a um bem específico, pois isso pode levar a uma violação de liberdades fundamentais ou então, ao uso opressivo da força do Estado para a estabilidade de determinada concepção comum de bem. Mas é evidente que em uma sociedade bem-ordenada, entendida como um sistema equitativo de cooperação, os cidadãos compartilham um objetivo comum: assegurar que as instituições sociais e políticas sejam justas. Não é verdade, portanto, que em uma sociedade liberal as pessoas não tenham objetivos comuns.

Por sua vez, um consenso sobreposto distancia-se dessa interpretação fundamentalmente por três características: (i) uma concepção política de justiça também é uma concepção é moral, ou seja, objeto de um consenso moral, (ii) uma concepção política de justiça é assegurada por razões morais (iii) e ambas (objeto moral e razões morais) se vinculam à estabilidade ${ }^{38}$. Isso significa que aqueles cidadãos que professam diferentes doutrinas que embasam a concepção política de justiça não lhe retirarão o apoio caso a força de sua própria doutrina se altere. O fato das pessoas endossarem a mesma concepção política de justiça em nada as afeta no que diz respeito a elas se tornarem menos religiosas ou então menos devotadas a certa concepção específica de bem. A característica da estabilidade deixa claro um contraste importante entre um consenso sobreposto e a ideia de modus vivendi, pois esta última exige um equilíbrio de forças para que se mantenha a estabilidade no que se refere à distribuição de poder, por exemplo ${ }^{39}$.

Outra comum objeção que é feita à ideia de consenso sobreposto é a de que ela resulta em uma concepção política de justiça baseada na indiferença ou no ceticismo, pois não sustenta a verdade de tal concepção, mas tão somente a razoabilidade da mesma em sentido construtivista. Essa objeção está fundada no pressuposto de que afirmar que uma concepção é a mais razoável pode dar a entender que ela pode ser razoável para nós, mas não verdadeira. Se assim o fosse, a verdade de uma teoria seria uma propriedade contingente e não necessária de sua constituição.

\footnotetext{
${ }^{37}$ A ideia de modus vivendi é expressa nos seguintes termos por Rawls. "O termo é comumente utilizado para caracterizar um tratado entre dois Estados cujos objetivos e interesses nacionais os colocam em conflito. Ao negociar um tratado, seria sensato e prudente que cada Estado agisse para assegurar que o acordo proposto represente um ponto de equilíbrio, isto é, que os termos e as condições do tratado sejam estabelecidos de tal maneira que seja de conhecimento público, não sendo vantajoso para nenhum dos dois violá-los. Respeitar-se-á o tratado, então, porque cada uma das partes considera que fazê-lo corresponde a seu interesse nacional, o que inclui o interesse de cada uma delas em manter a reputação de ser um Estado que cumpre os tratados. Mas, em geral, ambos os Estados estão dispostos a alcançar seus objetivos às expensas do outro e podem vir a fazê-lo caso as condições se alterem. Circunstâncias como essas esclarecem o sentido em que semelhante tratado é apenas um modus vivendi. Circunstancias similares se apresentam quando pensamos o consenso social como fundado em interesses próprios ou de grupos, ou como produto de barganha política" (RAWLS, 2011, p. 173).

${ }^{38}$ Falamos a respeito do problema que envolve a relação entre moral e política na nota 10. Mas esse não é um ponto pacífico da teoria de Rawls, o qual, por sinal, carece de maiores aprofundamentos.

${ }^{39}$ RAWLS, 2011, p. 174.
}

\begin{tabular}{|c|c|l|l|l|l|}
\hline intuitio & $\begin{array}{c}\text { ISSN } \\
1983-4012\end{array}$ & Porto Alegre & Vol.7- $\mathrm{N}^{\mathrm{o}} .1$ & $\begin{array}{c}\text { Junho } \\
2014\end{array}$ & p.125-138 \\
\hline
\end{tabular}


Grosso modo, a teoria utilitarista, a qual Rawls se defronta constantemente, pode ilustrar essa crítica $^{40}$. Bentham, no capítulo primeiro da obra Uma introdução aos princípios da moral e da legislação, argumenta a propósito do princípio da utilidade afirmando que ele deve ser entendido como aquela propriedade existente em qualquer coisa em virtude da qual um objeto tende a produzir prazer ou felicidade (utilidade) ou a evitar o seu contrário. Esses dois senhores soberanos (a dor e o prazer) que a natureza colocou o gênero humano sob domínio, evidencia no pensamento de Bentham uma verdade sagrada (true sacred) que deve pautar a vida moral e política de uma sociedade ${ }^{41}$.

Entretanto, Rawls responde essa crítica ressaltando que seria um enorme equívoco compreender a ideia de consenso sobreposto como uma forma de intuicionismo ou então como se previamente existisse uma ordem de valores já dados, uma vez que esse ceticismo ou indiferença em relação à verdade levariam inevitavelmente ao fracasso o objetivo de se alcançar tal ideia. Ademais,

\begin{abstract}
A questão fundamental não é negar e nem defender qualquer doutrina abrangente e, como cada cidadão concorda com cada uma delas, espera-se que todos possam aceitar a concepção política como razoável ou verdadeira, tomando por base a própria doutrina abrangente. O objetivo fundamental do consenso sobreposto em uma concepção política de justiça como equidade é descobrir uma base comum para o que é considerado razoável em um sistema democrático de uma sociedade bemordenada, não sendo necessário promover uma parte de uma doutrina abrangente mais do que o que é imprescindível ou útil para o objetivo específico do consenso político ${ }^{42}$.
\end{abstract}

Alguns críticos de Rawls também objetam contra a ideia de consenso sobreposto afirmando que a concepção de justiça adotada pela sociedade deve ser abrangente, visto que seria impossível resolver conflitos sobre a justiça sem o consentimento de doutrinas religiosas, filosóficas ou morais. No entanto, poderíamos replicar a essa objeção com a seguinte questão: como se resolverá os conflitos existentes entre diferentes concepções abrangentes de bem? Aparentemente, as respostas podem ser duas. Ou se impõe determinada concepção abrangente de bem fazendo o possível para mantê-la estável por meio do uso da força ${ }^{43}$, ou então se encontra um ethos $^{44}$ capaz dar significado a existência social e individual das pessoas. A primeira opção é naturalmente antidemocrática e a segunda parece ser uma resposta insuficiente ao problema que acima colocamos.

\footnotetext{
${ }^{40}$ Ao falar a respeito dessa objeção, Rawls não cita nenhuma teoria específica. Mas, segundo nos parece, seria possível exemplificar essa crítica a partir da teoria utilitarista, fundamentalmente em Bentham.

${ }^{41}$ BENTHAM, Jeremy; MILL, John Stuart. Uma introdução aos princípios da moral e da legislação. São Paulo: Abril Cultural, 1971. p. 3-4.

${ }^{42}$ SILVEIRA, Denis C. A justificação por consenso sobreposto em John Rawls. In: Philósophos, v. 12, p. 11-37, 2007. p. 20.

${ }^{43}$ Nesse caso, são incontáveis as situações históricas que atestam essa alternativa.

${ }^{44}$ Essa é, por exemplo, a posição de Sandel quando o mesmo afirma que "se uma sociedade justa requer um forte sentimento de comunidade, ela precisa encontrar uma forma de incutir nos cidadãos uma preocupação com o todo, uma dedicação ao bem comum. Ela não pode ser indiferente às atitudes e disposições, aos "hábitos do coração" que os cidadãos levam para a vida pública, mas precisa encontrar meios de se afastar das noções de boa vida puramente egoístas e cultivar a virtude cívica.[...] Uma política do bem comum teria como um de seus principais objetivos a reconstrução da infraestrutura da vida cívica" (SANDEL, Michael. Justiça: o que é fazer as coisa certa. $3^{\mathrm{a}}$ ed. Rio de Janeiro: Civilização Brasileira, 2011. p. 325-8).
}

\begin{tabular}{|c|c|l|l|l|l|}
\hline intuitio & $\begin{array}{c}\text { ISSN } \\
1983-4012\end{array}$ & Porto Alegre & Vol.7- $\mathrm{N}^{\circ} .1$ & $\begin{array}{c}\text { Junho } \\
2014\end{array}$ & p.125-138 \\
\hline
\end{tabular}


Por isso, do modo como Rawls a propõe, a ideia de consenso sobreposto parece ser a resposta adequada a esse problema. Além de estar baseada em valores políticos historicamente consagrados na cultura democrática moderna, a concepção política de justiça pode abranger de igual modo valores que não sejam políticos, adequando assim, ideias que também estejam presentes em doutrinas gerais e abrangentes. O consenso sobreposto deve-nos oferecer um acordo a respeito de uma concepção política de justiça que nos permita alcançar um acordo político ao menos sobre os elementos fundamentais das questões de justiça básica (estrutura básica da sociedade). Deste modo, a concepção política mais razoável para lidar com o fato do pluralismo deve ser liberal ${ }^{45}$.

Por fim, uma última objeção afirma que a ideia de consenso sobreposto é utópica, pois não existem forças (políticas, sociais e religiosas) suficientes para se chegar a um consenso sobreposto e, em caso de chegarmos, mantê-lo estável. Para defender a ideia de que o consenso sobreposto é possível e estável, Rawls rebate essa crítica em um esboço em dois estágios. O primeiro culmina em um consenso constitucional e o segundo em um consenso sobreposto ${ }^{46}$.

O consenso constitucional garante determinados princípios liberais de justiça política, os quais são aceitos simplesmente como princípios, uma vez que não se fundam em certas ideias de sociedade e de pessoa de uma cultura política pública. Nesse caso, o consenso é raso, insuficiente e restrito. Embora o consenso constitucional se dê a respeito de certos direitos e liberdades políticas fundamentais (tais como, liberdade de expressão, liberdade de ir e vir e direito a voto), seu alcance não abrange, por exemplo, a estrutura básica da sociedade, visto que ele limita-se tão somente aos procedimentos políticos do governo democrático.

O passo seguinte, então, consiste em transformar o consenso constitucional em um consenso sobreposto. Para isso, é necessário que os princípios e os ideais políticos de um consenso sobreposto sejam baseados em uma concepção política de justiça que esteja fundada em ideias básicas de sociedade e de pessoa. Os princípios políticos precisam ir além de apenas instituírem procedimentos democráticos. Eles precisam, agora, incluir a estrutura básica como um todo, ou seja, incluir direitos substantivos como a liberdade de consciência e a liberdade de pensamento, assim como a igualdade equitativa de oportunidades e a satisfação de certas necessidades básicas.

Para tanto, uma vez que o consenso constitucional esteja vigorando, os diversos grupos políticos têm de participar de um fórum de discussão pública expondo suas ideias e, ao mesmo tempo, dirigir-se aos outros grupos que não compartilham de suas doutrinas abrangentes. Esse movimento de justificação pública faz com que se torne racional para eles ir além do ambiente de suas próprias visões e criar concepções políticas que possam ser publicamente justificadas e aceitas pelos demais parceiros. Rawls entende que os diversos grupos políticos encaminham-se para a formulação de uma concepção política de justiça mais ampla, onde todos possam ter uma moeda comum de discussão e

${ }^{45}$ RAWLS, 2011, p. 185.

${ }^{46}$ RAWLS, 2011, p. 187

\begin{tabular}{|c|c|c|c|c|c|}
\hline intuitio & $\begin{array}{c}\text { ISSN } \\
1983-4012\end{array}$ & Porto Alegre & Vol.7 $-\mathrm{N}^{\circ} .1$ & $\begin{array}{c}\text { Junho } \\
2014\end{array}$ & p.125-138 \\
\hline
\end{tabular}


um fundamento mais profundo para assegurar a satisfação das necessidades básicas de todos os cidadãos ${ }^{47}$. Em outras palavras, dirigem-se a um consenso sobreposto.

\section{Considerações finais}

Como já ressaltamos, seria incorreto afirmar que a tese rawlsiana segundo a qual o justo tem primazia sobre o bem sustenta que a teoria da justiça como equidade constitui-se a despeito de qualquer ideia de bem. Muitos poderiam supor que essa prioridade implica em dizer que uma concepção política liberal de justiça não pode se valer de nenhuma ideia de bem, exceto em casos de concepções puramente instrumentais ou então em questões de preferências ou escolhas individuais ${ }^{48}$. Evidentemente nenhuma concepção de justiça pode fundar-se somente na ideia de justo ou de bem, pois ambas se complementam. A primazia do justo sobre o bem na teoria de Rawls tem o sentido de que os princípios de justiça não pressupõem nenhuma concepção específica de bem e de que eles colocam os limites às formas de vida pelas quais os cidadãos podem se empenhar em realizar as concepções de bem que julgam ser verdadeiras.

Por exemplo, quando Rawls realiza críticas à teoria utilitarista ${ }^{49}$, ele o faz no sentido de que o modo como os conceitos de justo e de bem estão relacionados no interior da teoria moral utilitária estão incorretos. De modo geral, Rawls define o bem do utilitarismo em termos de prazer obtido pela realização de desejos. Portanto, seguindo a estrutura acima, o correto será a concepção que define os meios necessários para a consecução desses desejos, sejam lá quais eles forem. As críticas rawlsianas se dirigem então exatamente ao modo como os conceitos de justo e de bem são relacionados no interior da teoria moral utilitarista. O problema do utilitarismo para Rawls não está na definição de bem dada por ele, mas tão somente no modo como a teoria moral utilitária está estruturada.

Não é preciso recorrer a casos drásticos para perceber que o problema do utilitarismo está nos sacrifícios que ele pode requerer dos cidadãos em função do bem em questão. Caso a desigualdade ou a privação da liberdade de um grupo de pessoas fosse necessário para a produção de uma maior quantidade de utilidade agregada, o utilitarismo poderia recomendar essa atitude. Sob este ponto de vista, não existem atos absolutamente proibidos de serem praticados. A estrutura teleológica ${ }^{50}$ adotada pelo utilitarismo pode ser demasiadamente exigente para com os cidadãos ou então levá-los a cometer atos ruins, de um ponto de vista moral. É exatamente por isso que o utilitarismo "não leva a sério a distinção entre pessoas ${ }^{51}$ ”, segundo Rawls.

\footnotetext{
${ }^{47}$ RAWLS, 2011, p. 196.

${ }^{48}$ RAWLS, 2011, p. 204.

49 Além do utilitarismo, Rawls também faz críticas ao perfeccionismo, especificamente ao modo que este compreende os conceitos de justo e de bem.

${ }^{50}$ A teleologia se sustenta fundamentalmente em duas premissas: (i) o bem é definido independentemente do justo (right) (ii) e o justo (right) é aquilo que maximiza o bem (good).

${ }^{51}$ RAWLS, 2011, p. 230.
}

\begin{tabular}{|c|c|l|l|l|l|}
\hline intuitio & $\begin{array}{c}\text { ISSN } \\
1983-4012\end{array}$ & Porto Alegre & Vol.7- $\mathrm{N}^{\circ} .1$ & $\begin{array}{c}\text { Junho } \\
2014\end{array}$ & p.125-138 \\
\hline
\end{tabular}


Desse modo, para se compreenda o que de fato Rawls quer dizer quando afirma que o justo tem primazia sobre o bem, é preciso que se tenha claro que isso só é possível quando se relacionam corretamente as ideias de consenso sobreposto e de justiça como equidade como uma teoria política e não metafísica ou epistemológica. A força da proposta de filosofia de Rawls está no fato dela permitir uma diversidade de concepções de bem e, ao mesmo tempo, estabelecer os seus limites. Desse modo, a validade dos princípios não está associada à escolha de determinada concepção de bem, uma vez que a teoria de Rawls fixa o que é o justo a despeito das diversas concepções abrangentes de bem existentes na sociedade.

\section{Referências}

BRAGA, Antonio F. S. Kant, Rawls e o utilitarismo: justiça e bem na filosofia política contemporânea. Rio de Janeiro: Contraponto, 2011.

BENTHAM, Jeremy; MILL, John Stuart. Uma introdução aos princípios da moral e da legislação. São Paulo: Abril Cultural, 1971.

FORST, Rainer. Contextos de Justiça: filosofia política para além de liberalismo e comunitarismo. São Paulo: Boitempo, 2010.

KANT, Immanuel. Fundamentação da metafísica dos costumes. Trad. de Guido Antônio de Almeida. São Paulo: Discurso Editorial: Barcarolla, 2009.

KORSGAARD, Christine M. Realism and Constructivism in Twentieth-Century Moral Philosophy. In: Philosophy in America at the Turn of the Century. Journal of Philosophical Research, 2003, p. 99-122.

LYONS, David. Forms and limits of utilitarianism. Oxford: Oxford University Press, 2002.

MILL, John Stuart. A liberdade. São Paulo: Martins Fontes, 2000.

RAWLS, John. Justiça e democracia; tradução Irene A. Paternot; seleção, apresentação e glossário Catherine Audard. São Paulo: Martins Fontes, 2000.

. O Liberalismo político. 1 ed. amp. São Paulo: M. Fontes, 2011.

Uma teoria da justiça. 3.ed. rev. São Paulo: M. Fontes, 2008.

The Independence of moral theory. FREEMAN, Samuel. Collected Papers. Cambridge: Cambridge University Press, 1999.

SANDEL, Michael. Justiça: o que é fazer as coisa certa. $3^{\text {a }}$ ed. Rio de Janeiro: Civilização Brasileira, 2011.

SILVEIRA, Denis Coitinho da. Posição Original e Equilíbrio reflexivo em John Rawls: o Problema da Justificação. In: Trans/Form/Ação, vol.32, no.1, 2009.

Epistemologia Coerentista em Rawls. In: Dissertatio [34], 2011.

A justificação por consenso sobreposto em John Rawls. In: Philósophos, v. 12, p. 11-37, 2007.

VITA, Álvaro de. A justiça igualitária e seus críticos. $2^{\circ}$ ed. São Paulo: WFM Martins Fontes, 2007.

Recebido em: 30/04/2014

Aprovado para publicação: 22/05/2014

\begin{tabular}{|c|c|l|l|l|l|}
\hline intuitio & $\begin{array}{c}\text { ISSN } \\
1983-4012\end{array}$ & Porto Alegre & Vol.7 $-\mathrm{N}^{\mathrm{o}} .1$ & $\begin{array}{c}\text { Junho } \\
2014\end{array}$ & p.125-138 \\
\hline
\end{tabular}

